\title{
La Escala de Identidad Etnica Multigrupo (EIEM) en el contexto costarricense
}

\author{
Vanessa Smith Castro
}

\begin{abstract}
Resumen
El presente artículo describe las propiedades psicométricas de un instrumento para la medición de la identidad étnica y sus componentes en jóvenes costarricenses: la "Escala de Identidad Etnica Multigrupo" (EIEM) desarrollada por Phinney (1992). En el estudio participaron 287 jóvenes afrocostarricenses, 768 jóvenes "blancos" o mestizos y 120 jóvenes de procedencia étnica mixta. Análisis factoriales confirmatorios demuestran que la escala mide dos componentes de la identidad étnica altamente relacionados en todos los grupos estudiados: afirmación e identificación étnica y exploración étnica. Análisis de confiabilidad revelan índices de consistencia interna (Alfas de Cronbach) satisfactorios para todos los grupos. La escala muestra relaciones moderadas con mediciones de orientaciones hacia los colectivos de referencia y conductas intergrupales como las actitudes hacia la aculturación y está positivamente relacionada con índices de autoestima e identidad del yo.
\end{abstract}

\begin{abstract}
The present article describes the psychometric properties of an instrument for the assessment of ethnic identity and its components among Costa Rican adolescents: the "Multigroup Ethnic Identity Measure" (MEIM) developed by Jean Phinney (1992). Participants were 287 AfroCosta Rican, 768 White/Mestizo, and 120 of mixed ancestry adolescents. Confirmatory factor analyses show that the measure assess two different but highly related components of ethnic identity across groups: ethnic affirmation/identification, and ethnic exploration. Reliability analysis yielded satisfactory Cronbach's alphas across groups. The scale is moderately related to measures of ingroup orientation and intergroup behaviors as such as acculturation attitudes, and is positively related to indices of self-esteem and ego-identity.
\end{abstract}

${ }^{1}$ La presente investigación fue en parte financiada por una beca otorgada a la autora entre 1999 y el 2001 por la Friedrich-Ebert-Stiftung de Alemania. 


\section{Introducción}

El significado subjetivo de pertenecer a un grupo étnico o "identidad étnica" ha sido históricamente reconocido como un componente central de la definición del sí mismo y un importante regulador de la conducta intergrupal (Allport, 1954; Mead, 1934; Tajfel, 1981). Especialmente para aquellos que son víctimas de la discriminación racial y étnica, la relación cognitiva y emocional con el grupo étnico de referencia se hace aún más relevante para la evaluación y valoración personal. En el ámbito internacional, el interés por entender la identidad étnica ha llevado a una importante producción de investigaciones sobre el tema (Phinney, 1990). Estas investigaciones muestran que la identidad étnica es un constructo multidimensional y complejo, determinado por la interacción de factores interindividuales, contextuales y socioestructurales. Asimismo, el papel de la identidad grupal en la regulación del comportamiento social ha sido demostrado consistentemente en un número importante de investigaciones dentro y fuera del laboratorio (Wagner, 1994).

En el ámbito nacional, el reconocimiento de la diversidad étnica y cultural que caracteriza a nuestro país ha puesto de relieve la necesidad de estudiar más sistemáticamente el impacto psicosocial de pertenecer a colectivos étnicos y en particular a los grupos étnicos minoritarios. Según el Censo 2000, además de la amplia mayoría "blanca" o mestiza, aproximadamente el 2\% $(\mathrm{N}=72.784)$ de la población costarricense se autodefine como afrocostarricense, $1,7 \%(\mathrm{~N}=63.800)$ pertenece a las diversas comunidades indígenas del país y el $0,2 \%(\mathrm{~N}=7.800)$ se identifica a sí misma como chinocostarricense (INEC, Censo Nacional de Población y Vivienda 2000). Estudios anteriores han demostrado también que en nuestro país opera un complejo sistema de discriminación en contra de las minorías afrocostarricenses, chino-costarricenses e indígenas del país (Duncan y Powel, 1988; Meléndez y Duncan, 1981; Sawyers y Perry, 1998; Smith, 1995).

El presente artículo intenta contribuir al análisis de esta realidad por medio de la adaptación de un instrumento de medición de la identidad étnica al contexto costarricense: la Escala de Identidad Etnica Multigrupo (EIEM) ${ }^{2}$. Esta escala fue concebida por Phinney (1992) para medir varios aspectos de la identidad étnica en población adolescente. El objetivo central del presente estudio es poner a prueba las características psicométricas de esta escala en una muestra de jóvenes costarricenses de tres procedencias étnicas (afrocostarricenses, "blancos" o mestizos y de procedencia mixta o mulatos) y profundizar así en el conocimiento sobre la identidad étnica y sus componentes en nuestro medio.

\section{La identidad étnica y sus componentes}

Una revisión de la literatura empírica publicada en los últimos 10 años evidencia una gran variedad en la conceptualización y operacionalización de la identidad étnica. No obstante, parece existir un consenso general en definir la identidad étnica como una especificación de la identidad social tal y como ha sido propuesto por Tajfel (1981), es decir, "como aquella parte del autoconcepto de un individuo que se deriva del conocimiento de su pertenencia a un grupo social (o grupos sociales) junto con el significado valorativo y emocional asociado a dicha pertenencia" (p. 292 , itálicas en el original). Sobre la base de esta definición general, muchos investigadores se han ocupado de la multidimensionalidad del constructo tratando de diferenciar empíricamente sus componentes (Luhtanen y Crocker, 1992; Ellemers, Kortekaas y Ouwerkerk, 1999; Klink, Mummendey, Mielke, y Blanz, 1997; Phinney, 1990; Verkuyten y Lay, 1998). Esta literatura define al menos cinco componentes. Tres de ellos, surgen de la conceptualización propuesta por Tafjel (1981) quien distinguía "[un] componente cognitivo, en el sentido del conocimiento de que uno pertenece a un grupo; [un] componente evaluativo, en el sentido de que la noción de grupo y/o de la pertenencia de uno a él puede tener una connotación valorativa positiva o negativa; y [un] componente emocional, en el sentido de que los aspectos cognitivo y evaluativo del grupo y de la propia pertenencia a él pueden ir acompañados de emociones tales como amor u odio, agrado o desagrado hacia el propio grupo o hacia grupos que mantienen ciertas relaciones con él" (p. 264, itálicas en el original).

\footnotetext{
2 Título original: Multigroup Ethnic Identity Measure (MEIM).
} 
Dentro de esta misma línea teórica, se ha introducido recientemente la distinción de un cuarto componente como el componente comportamental o conativo (p. ej. van Dick y Wagner, en prep). Finalmente, un quinto componente ha sido propuesto desde los modelos del desarrollo de la identidad étnica (Cross, 1990, Phinney, 1990) como el componente de la realización o elaboración de la identidad (ethnic identity achievement). Veamos.

El componente cognitivo de la identidad étnica o "autoidentificación étnica" se refiere al uso de una etiqueta étnica para describirse a sí mismo. Cuando los individuos usamos una etiqueta étnica, nos definimos en términos de las similitudes que compartimos con otros miembros de una misma categoría étnica o endogrupo y nos diferenciamos de los miembros de otras categorías étnicas o exogrupos. (Turner, Oakes, Haslam, y McGarty, 1994). Con respecto a su operacionalización, la autoidentificación étnica ha sido evaluada preguntando directamente a los individuos por las categorías étnicas a las que pertenecen, o presentando ítems tales como "yo me considero a mí mismo(a) como miembro de mi grupo" (Klink et. al., 1997).

El componente evaluativo hace referencia a las connotaciones valorativas asociadas con la pertenencia a un grupo étnico, se trata aquí de la valencia de las actitudes hacia la propia etnicidad. Para muchos autores este componente es mejor entendido como orgullo o "afirmación étnica" (p. ej. Aboud y Doyle, 1995). Este componente ha sido medido de muy diversas formas. En estudios con adolescentes y adultos, las actitudes han sido medidas pidiendo a los participantes evaluar su etnicidad utilizando listas de adjetivos positivos y negativos (p. ej., Ichiyama, Mcquarrie, y Ching, 1996), con preguntas del tipo "si usted pudiera escoger, ¿le gustaría ser Turco o no? (Verkuyten, 1990), o por medio de ítems como "Pienso que mi grupo étnico no tiene mucho por lo que deba sentirse orgulloso" (Ellemers, Kortekaas, y Ouwerkerk 1999), o "estoy orgulloso de ser chino (a)" (Rosenthal y Feldman, 1992).

El componente afectivo hace referencia al vínculo emocional o cercanía psicológica con el grupo étnico de referencia. La operacionalización de este componente o "identificación étnica" incluye ítems como "me siento fuertemente ligado a la gente negra" (Helms, 1990), o "en general, pertenecer a mi grupo étnico es una parte importante de la percepción que tengo de mí mismo(a)" (Luhtanen y Crocker, 1992).

El componente comportamental se refiere a la participación activa (o bien la intención de participar) en las practicas culturales del grupo étnico de referencia. Usualmente se mide usando preguntas directas sobre usos del lenguaje, afiliación religiosa, expresiones artísticas y conocimientos sobre la historia y cultura del propio grupo (Ward y Kennedy, 1994). Por ello, este componente ha sido comúnmente denominado "prácticas o conductas étnicas".

El quinto componente, como ya se mencionó, surge de la psicología social del desarrollo. Basados en el trabajo de Erikson (1973), los modelos del desarrollo conceptualizan la formación de la identidad étnica como una tarea básica de la adolescencia, cuyo eje es la integración de identificaciones tempranas, inclinaciones personales y ofrecimientos socioculturales. Así por ejemplo, Phinney (1990) asume que el proceso de desarrollo de la identidad étnica sigue una lógica de desarrollo similar al del desarrollo de la identidad del yo. La autora establece tres etapas en la formación de la identidad étnica. La primera de ellas, denominada “identidad étnica no examinada”, se caracteriza por la ausencia de una exploración y toma de decisiones en relación con la etnicidad. Sigue a ésta un período denominado "exploración de la identidad étnica". El resultado de este proceso de búsqueda sería la "identidad étnica internalizada", caracterizada por una comprensión y apreciación más profunda de la propia etnicidad. El componente de desarrollo o "elaboración de la identidad étnica" ha sido operacionalizado por medio de ítems como "con el fin de aprender más sobre mi tradición cultural, he conversado con otras personas acerca de mi grupo étnico" (Phinney, 1992).

En suma, las conceptualizaciones recientes sobre la identidad étnica hacen énfasis en el carácter multidimensional del constructo, asumiendo que sus componentes contribuyen de manera diferente al sentimiento de pertenencia a los colectivos étnicos de referencia. Si bien el reconocimiento de la multidimensionalidad del constructo permite un acercamiento más diferenciado a la identidad étnica, esto trae consigo un problema central para su operacionalización: ¿se pueden diferenciar empíricamente estos componentes de la identidad?. Si esto es así, ¿cómo acceder a ellos de manera consistente? 


\section{La escala de identidad étnica multigrupo}

En respuesta a estas interrogantes, la literatura actual ofrece un sinnúmero de escalas para la medición de la identidad étnica y sus componentes (Helms, 1990; Sellers, Smith, Shelton, Rowley y Chavous, 1998; Valk y Koru, 2001). Éstas, sin embargo, han sido desarrolladas para grupos étnicos específicos, atendiendo a las particularidades culturales e históricas de cada grupo. Esto representa una ventaja en términos del estudio de la especificidad cultural, pero a la vez una desventaja ya que así se restringen las posibilidades de reconocer diferencias y similitudes en la identidad étnica en distintos grupos sobre una base común. La EIEM fue desarrollada precisamente para superar esta limitación. En la tabla 1 se presentan los ítems de la versión costarricense de la escala ordenados de acuerdo a los componentes que pretenden medir.

\section{Tabla 1}

\section{Escala de Identidad Etnica Multigrupo}

- Afirmación étnica

- Estoy feliz de ser miembro de mi grupo étnico.

- Me siento fuertemente ligado(a) a mi grupo étnico.

- Me siento muy comprometido(a) con mi grupo étnico

- Me siento muy bien con mi tradición étnica o cultural.

- Estoy muy orgulloso(a) de mi grupo étnico.

- Elaboración de la identidad étnica

- Últimamente me he dedicado a conocer más sobre la historia, tradiciones y costumbres de mi grupo étnico.

- Estoy consciente de mis „raíces étnicas“ y de lo que éstas significan para mí.

- Realmente no sé cuál es el papel que juega mi grupo étnico en mi vida. a

- La verdad es que no me he preocupado por aprender más sobre la cultura e historia de mi grupo étnico. ${ }^{\text {a }}$

- Con el fin de aprender más sobre mi tradición cultural, he conversado con otras personas acerca de mi grupo étnico.

- Entiendo perfectamente lo que significa para mí pertenecer a mi grupo étnico.

- Me pongo a pensar mucho sobre cómo se podría ver afectada mi vida por el hecho de pertenecer a mi grupo étnico.

- Conductas étnicas

- Asisto a grupos y organizaciones que están compuestas, en su mayoría, por personas de mi grupo étnico.

- Participo activamente de las tradiciones de mi grupo étnico como por ejemplo de su música, comida, idioma, etc.

- Asisto a organizaciones y participo en actividades en donde se promueven las tradiciones de mi grupo étnico b

Nota. Tomada y traducida de Phinney (1992, pags. 172-173).

a El ítem es eliminado de la nueva versión.

b Nuevo ítem desarrollado para la versión costarricense. 
Como se puede observar, Phinney (1992) desarrolla originalmente una escala de 14 ítems que pretenden medir tres componentes de la identidad étnica comunes a varios grupos étnicos. Cinco ítems miden afirmación e identificación étnica, siete ítems miden el componente de desarrollo y dos ítems miden conductas étnicas. A diferencia de la escala original, la versión costarricense incluye un tercer ítem para medir conductas étnicas, que permite complementar los dos originales ("participo activamente en organizaciones que promueven las tradiciones de mi grupo étnico"). Los ítems son contestados en una escala Likert de cuatro puntos, en donde altas puntuaciones reflejan una orientación fuerte y positiva hacia el grupo étnico de referencia. El instrumento inicia con una pregunta abierta para medir autoidentificación étnica (“‘a cuál grupo étnico pertenece usted?”) y termina con una pregunta de selección múltiple en donde los participantes pueden escoger de una lista preparada por el(la) investigador(a) aquella(s) etiqueta(s) étnica(s) más apropiadas para definirse a sí mismos y cada uno de sus padres.

Recientemente, la escala ha sido sometida a diversos cambios por parte de su autora: algunos ítems han sido mejorados en su redacción y la escala ha sido reducida a 12 ítems (ítems 8 y 9 de la tabla 1 fueron eliminados; Phinney, comunicación personal, agosto, 1998).

La EIEM ha sido ampliamente utilizada en una gran variedad de grupos étnicos en distintos contextos culturales mostrando una buena consistencia interna indicada por Alfas de Cronbach superiores a .80 , así como correlaciones consistentes con mediciones de autoestima y ajuste psicológico (Lorenzo-Hernández y Ouellette, 1998; Martínez y Dukes, 1997; Phinney, Cantu, y Kurtz, 1997). Sin embargo, la escala parece no reproducir la multidimensionalidad que se le atribuye. Los análisis factoriales exploratorios apuntan hacia una estructura unidimensional, por lo que el promedio de las respuestas a todos los ítems ha sido comúnmente utilizado como indicador global del grado de identificación positiva con el endogrupo. Sin embargo, recientemente Roberts, Phinney, Masse, Chen, Roberts y Romero (1999) realizaron análisis factoriales confirmatorios de la nueva escala en una muestra de 5.423 jóvenes de diversos grupos étnicos, confirmándose la existencia de dos factores latentes altamente correlacionados $\left(r_{s} \geq .70\right)$. El primer factor incluye aquellos ítems destinados a medir afirmación e identificación étnica, así como los ítems que miden conciencia de la propia etnicidad (ítems 7 y 11 de la tabla 1), mientras que el segundo factor reúne los ítems correspondientes a los componentes comportamental y del desarrollo, denominado por los autores cómo exploración de la identidad étnica.

Si bien Roberts et al. (1999) demuestran que la estructura bidimensional se ajusta de manera adecuada a los datos en los diferentes grupos étnicos estudiados, la decisión de asumir esta estructura para el contexto costarricense debería apoyarse también en la superioridad de su ajuste con respecto a otras estructuras plausibles; ésto debido a que el modelo de Roberts et al. (1999) se basa en resultados de análisis factoriales exploratorios en muestras estadounidenses. Por ello, uno de los objetivos centrales del presente estudio es examinar con más detalle la estructura de la identidad étnica en el contexto nacional.

\section{Estructura y criterios de validez}

El presente estudio evalúa tres modelos o formas de representar la covaración de los ítems de la escala. El primer modelo supone, sobre la base de resultados empíricos previos, que la escala es unidimensional. Un segundo modelo reflejaría la intención inicial de la escala de medir tres componentes diferentes pero interrelacionados de la identidad: 1) afirmación e identificación étnica, 2) el componente del desarrollo y 3) prácticas étnicas. Nótese que la escala original sólo incluye dos ítems para medir este último componente, lo que hace difícil construir con ellos una subescala adecuada. Como ya se mencionó, para saber si las conductas étnicas representan un factor distinguible de la identidad étnica, la versión costarricense incluye un tercer ítem para complementar los dos originales ("participo activamente en organizaciones que promueven las tradiciones de mi grupo étnico"). Finalmente, un tercer modelo asume, en concordancia con Roberts et al. (1999), que la escala refleja dos componentes diferentes pero relacionados de la identidad étnica: afirmación e identificación étnica por un lado y la exploración de la identidad étnica por el otro. Determinar cuál de estos tres modelos representa de manera más adecuada la covariación de los ítems en las muestras costarricenses, proporcionaría importante información sobre cómo los jóvenes están entendiendo los reactivos presentados y sobre la forma más adecuada de utilizar la escala en nuestro contexto. La posibilidad de contrastar otros modelos teóricamente 
plausibles se excluye por los límites que impone el instrumento. Recuérdese por ejemplo que el componente cognitivo se mide con una pregunta abierta y una pregunta de selección múltiple.

Además de abocarse al problema de la estructura de la escala, se examinará aquí la confiabilidad y validez de constructo del instrumento. Estudios anteriores han utilizado por lo general tres criterios de validez: 1) La correlación de EIEM y la edad de los entrevistados, 2) la correlación entre la escala y mediciones de la autoestima y 3) diferencias en la identidad étnica entre miembros de grupos étnicos minoritarios y mayoritarios (ver Phinney, 1992; Roberts et al., 1999). Debido a que la escala pretende ser sensible a cambios ligados al desarrollo individual se esperaría variaciones en la identidad étnica ligados a la edad. En este estudio sin embargo, este criterio no será examinado debido a que la muestra es muy homogénea a este nivel. En lugar de ello, este estudio incluye tres criterios más: la asociación de la escala con mediciones de la identidad del yo (Rosenthal, Gurney y More, 1981), tendencias colectivistas (Triandis, Bontempo, Villareal, Asai, y Lucca, 1989) y las actitudes hacia la aculturación (Berry, 1984). A continuación se explican en detalle los criterios de validez.

\section{Identidad étnica, identidad del yo y autoestima.}

Tanto la Teoría de la Identidad Social (TIS) (Tajfel y Turner, 1979), como los modelos del desarrollo de la identidad étnica asumen que ésta última, la identidad de yo y la autoestima están positivamente relacionadas. Según la TIS, la identidad social y personal representan dos componentes distintos del autoconcepto. La TIS supone además que los grupos sociales de referencia son una fuente importante de valoración personal, de tal manera que una autoestima colectiva positiva estaría acompañada de una autoestima personal también positiva. Por su parte, el enfoque del desarrollo de la identidad étnica supone también un paralelismo entre el desarrollo de la identidad grupal y la identidad del yo (Phinney, 1990). Teóricamente, la difusión étnica podría estar acompañada de sentimientos de inadecuación en el ámbito de la identidad del yo, lo cual a su vez puede también repercutir en la imagen y evaluación personal. Por ello se espera aquí que la EIEM esté positivamente relacionada con escalas de identidad del yo y autoestima personal. Ahora bien, si la escala mide un constructo distinto, como es de esperarse, tales correlaciones deberían ser moderadas. Correlaciones positivas muy altas serían un indicador de que se está midiendo prácticamente el mismo constructo.

\section{Identidad étnica y colectivismo.}

Según Triandis et al. (1988) no sólo las culturas, sino también las personas difieren en términos del papel que juegan los endogrupos (familia, vecinos, amigos, compatriotas) en la regulación de su comportamiento y la definición del sí mismo. Los colectivistas (o bien alocentristas) tienden a definir su identidad personal en términos de su pertenencia a grupos sociales, subordinan los objetivos personales a las metas grupales, se preocupan por los efectos que su conducta puede causar a otros cercanos, tienden a compartir sus recursos con otros miembros del endogrupo y establecen vínculos de interdependencia con ellos. Debido a que la EIEM es una medición del significado subjetivo de pertenecer a un grupo étnico, podría existir cierto traslape entre las orientaciones colectivistas y la identidad étnica. La EIEM sin embargo, no debería medir una tendencia general a valorar la pertenecía a colectivos, sino un vínculo psicológico particular con el grupo étnico de referencia. Por ello se espera que la escala muestre relaciones positivas pero moderadas con mediciones de tendencias colectivistas.

\section{Identidad étnica y actitudes hacia la aculturación.}

Las actitudes hacia la aculturación se definen como las representaciones que tiene los individuos y grupos acerca de cómo deberían interactuar los miembros de distintos grupos étnicos en la sociedad (Berry, 1984). Estas orientaciones emergen de dos dimensiones de aculturación independientes: el mantenimiento cultural y el contacto interétnico. Aunque se han definido cuatro orientaciones básicas, dos de ellas son relevantes para los propósitos de la presente investigación: la 
integración y la asimilación. Integración es la representación de que todos los grupos étnicos en la sociedad deben tener la posibilidad de mantener sus tradiciones culturales y a la vez participar activamente en la vida social, cultural y política del país. Por el contrario la asimilación es la idea de que los grupos étnicos (en particular los minoritarios) deberían abandonar sus practicas culturales específicas para poder participar en la sociedad (Berry, Kim, Power, Young y Bujaki, 1989). Si la EIEM mide adecuadamente la afirmación étnica y el involucramiento con las prácticas culturales del grupo de referencia, entonces es de esperarse que la escala muestre correlaciones positivas con mediciones de las tendencias a la integración y correlaciones negativas con mediciones de tendencias a la asimilación.

\section{Diferencias en la identidad étnica por grupos étnicos.}

Debido a que miembros de grupos étnicos minoritarios estigmatizados están más frecuentemente expuestos al prejuicio y discriminación que los miembros de grupos étnicos dominantes, se esperaría que la etnicidad sea más relevante para la definición del sí mismo en los primeros que en los últimos. Existe evidencia empírica de que miembros de grupos mayoritarios algunas veces ni siquiera se ven a sí mismos como miembros de un grupo étnico (Phinney, 1992). Así, si la EIEM mide adecuadamente el constructo que pretende medir, entonces se esperaría que los jóvenes del grupo afrocostarricense obtuvieran puntuaciones más altas en la escala que los jóvenes pertenecientes al grupo mayoritario mestizo. Debido a la poca información que se tiene hasta ahora sobre la identidad étnica en grupos de procedencia mixta tanto en el ámbito nacional como internacional, no se puede adelantar ninguna hipótesis sobre las puntuaciones de los jóvenes mulatos.

\section{Método}

\section{Participantes en el estudio}

Las hipótesis anteriormente descritas fueron examinadas en una muestra de 1.175 estudiantes de colegios públicos de San José y Limón. De ellos, 287 se clasificaron a sí mismos como afrocostarricenses, 768 cómo "blancos" o mestizos y 120 como una mezcla entre estos dos grupos (ver tabla 2). La etiqueta étnica que utilizan los jóvenes para definirse a sí mismos no siempre coincide con la etnicidad atribuida a los padres. Además, durante la recolección de los datos se hizo patente que para algunos jóvenes era difícil ubicar la procedencia étnica de sus padres. Detallar las frecuencias de todas las 60 combinaciones posibles que surgen de la información de los jóvenes va más allá de los objetivos de este estudio. Más importante es reconocer que dentro del grupo de jóvenes que se definen a sí mismos como afrocostarricenses, 68 (28.3\%) reportan una procedencia multiétnica (es decir sólo uno de los padres proviene del grupo étnico afrocostarricense). Así mismo, en el grupo mestizo/blanco 52 jóvenes $(21.7 \%)$ reportan una procedencia bicultural.

Tabla 2

Distribución de la autoidentificación étnica

\begin{tabular}{|lcccccc|}
\hline & \multicolumn{1}{c}{ Padre } & \multicolumn{3}{c}{ Madre } & \multicolumn{2}{c|}{ Entrevistado } \\
\cline { 2 - 7 } Autoidentificación étnica & $\mathrm{f}$ & $\%$ & $\mathrm{f}$ & $\%$ & $\mathrm{f}$ & $\%$ \\
\hline Afrocostarricenses & 317 & 27.0 & 287 & 24.4 & 287 & 24.4 \\
Mestizo/Blanco & 798 & 67.9 & 840 & 71.5 & 768 & 65.4 \\
Mulatos & 18 & 1.5 & 16 & 1.4 & 120 & 10.2 \\
Indígenas & 18 & 1.5 & 16 & 1.4 & - & - \\
Asiáticos & - & - & 2 & .2 & - & - \\
\hline Ns/Nr & 24 & 2.0 & 14 & 1.2 & - & - \\
\hline Total & 1175 & 100 & 1175 & 100 & 1175 & 100 \\
\hline
\end{tabular}


El rango de edad de todos los participantes es de 13 a 24 años $(M=16.05, S=1.54)$. Seis de los participantes no indicaron su edad. Análisis de varianza simple indican diferencias de edad estadísticamente significativas entre los grupos étnicos, $F(2,1166)=9.24, p<001$. La prueba Tukey HSD indica que los jóvenes afrocostarricenses $(M=16.39)$ son mayores $\left(\phi_{\mathrm{s}}<.05\right)$ que los jóvenes mestizos y mulatos $\left(M_{\mathrm{s}}=15.94\right)$.

En general participaron más mujeres que hombres en el estudio $(58 \%, 60 \%$ y $65 \%$ en el grupo afrocostarricense, mestizo y mulato respectivamente).

$\mathrm{El} \mathrm{70 \%} \mathrm{de} \mathrm{los} \mathrm{jóvenes} \mathrm{afrocostarricenses} \mathrm{y} \mathrm{el} \mathrm{76 \%} \mathrm{de} \mathrm{los} \mathrm{jóvenes} \mathrm{mulatos} \mathrm{provienen} \mathrm{de} \mathrm{la}$ provincia de Limón. Los participantes mestizos están equitativamente distribuidos en ambas provincias.

Utilizando como indicador el oficio o profesión de los padres, se observa que los participantes provienen de estratos socioeconómicos medios y bajos. En todos los grupos se encontró una asociación entre vivir en Limón y provenir de estratos bajos $\left(\chi^{2}(1,1.116)=50.05\right.$, $p<$ $.001)$.

\section{Instrumentos}

Todos los instrumentos utilizados para el presente estudio fueron contestados con una escala Likert de seis puntos $(1=$ totalmente en desacuerdo, $6=$ totalmente de acuerdo). El cambiar la escala de respuesta de la EIEM obedeció a la necesidad de aumentar el rango de variabilidad. El promedio de las respuestas a los ítems fue utilizado como indicador de los constructos (después de recodificar los ítems negativos, en caso dado). Altas puntuaciones en las escalas indican altos niveles en cada constructo.

"Identidad étnica" fue medida con una versión de 13 ítems de la nueva EIEM, incluyendo el ítem elaborado para complementar la subescala de conductas étnicas.

La autoestima fue medida por medio de la Escala de autoestima de Rosenberg (Rosenberg, 1965). Esta escala está compuesta por 10 ítems (p. ej. "siento que soy una persona tan valiosa como las demás”). Los Alfas de Cronbach de la escala son .73, .74, y .71 para el grupo afrocostarricense, mestizo y bicultural, respectivamente.

"Identidad del yo" se midió por medio de ocho ítems de la subsescala "Identidad versus Difusión" del "Inventario de los estadios psicosociales de Erikson" desarrollado por Rosenthal, Gurney y Moore (1981). Cuatro de los ítems reflejan estabilidad en la definición personal (ej. "tengo una idea muy clara de lo que quiero ser"), mientras que los otros cuatro reflejan confusión ("realmente no sé quién soy"). La escala muestra índices de consistencia aceptables en todos los grupos (.71, .74 y .72 para el grupo afrocostarricense, mestizo y mulato, respectivamente).

"Las orientaciones colectivistas" fueron medidas a través de nueve ítems de la Escala INDCOL desarrollada por Hui (1988), (ej. ítem negativo: "uno debería vivir su vida lo más independientemente posible”). Los Alfas de Cronbach de la escala son .63 para los grupos afrocostarricense y mestizo y .60 para el grupo mulato.

"Las actitudes hacia la aculturación" se midieron sobre la base de la "Escala de aculturación" desarrollada por van Dick, Wagner, Adams, y Petzel (1997), y algunos ítems desarrollados especialmente para el contexto costarricense. Cinco ítems reflejan aceptación de las políticas de integración (ej. "la convivencia entre distintos grupos étnicos sería más adecuada si cada grupo tuviera la oportunidad de mantener sus propias costumbres"). La consistencia interna de estos ítems es de .54, .56 y .62. para los jóvenes afrocostarricenses, mestizos y mulatos respectivamente. Cuatro ítems miden actitudes positivas hacia la asimilación (ej. "los extranjeros y los grupos étnicos que tienen costumbres diferentes a la mayoría de los costarricenses no deberían mostrarlas en público"). Estos ítems tienen Alfas de .63 para el grupo afrocostarricense y .66 para el grupo mestizo y mulato.

\section{Procedimiento}

Todas las escalas fueron sometidas a un proceso de adaptación que incluía la evaluación de la traducción por parte de evaluadores externos y la estimación de las características psicométricas de los instrumentos en un estudio piloto con 146 jóvenes universitarios afrocostarricenses y mestizos. 
Para el presente estudio, el cuestionario fue aplicado en tres colegios en Limón y cinco en San José. Los estudiantes llenaron el cuestionario en sus respectivas aulas. Llenar el cuestionario les tomó entre 30 y 35 minutos. Se aseguró completo anonimato y la participación fue voluntaria. La cuota de respuesta fue de un $94 \%$.

\section{Resultados}

\section{Estructura de la EIEM}

Análisis de factores exploratorios. Si bien este estudio tiene una fuerte base teórica y empírica para realizar los análisis de factores confirmatorios directamente, la combinación de análisis exploratorios y confirmatorios es comúnmente recomendada (ver Wegener y Fabrigar, 2000). Es por ello que en preparación a los análisis confirmatorios se realizaron análisis factoriales exploratorios. Ahora bien, el realizar los análisis exploratorios con toda la muestra socava el carácter confirmatorio de los análisis que se desean realizar en este estudio. Es por ello que los análisis exploratorios se llevaron a cabo con una submuestra elegida al azar de 150 jóvenes de los tres grupos. Esta submuestra estaba compuesta por 38 jóvenes afrocostarricenses, 102 jóvenes mestizos y 10 jóvenes de procedencia mixta o "mulatos". Aquí, la escala fue sometida a un análisis de componentes principales con rotación Varimax. Con el fin de examinar la idoneidad del análisis factorial, la matriz de correlaciones entre todos los ítems fue previamente examinada. Todos los ítems presentan relaciones substanciales con los otros ítems, con excepción del ítem número 12 de la tabla 1 ("me pongo a pensar mucho sobre cómo se podría ver afectada mi vida por el hecho de pertenecer a mi grupo étnico"), el cual presenta correlaciones menores a .24 con los demás. Este ítem además obtuvo la comunalidad más baja de todos (.39), por lo que fue eliminado del análisis. Una vez eliminado este ítem, el análisis de factores reveló tres factores con un valor propio (Eigenvalue) mayor de 1 que en su totalidad explican un 56\% de la varianza de los ítems (ver tabla 3).

Tabla 3

Cargas factoriales de los ítems de la versión costarricense de la EIEM en una muestra elegida al azar de 150 jóvenes de los tres grupos étnicos

\begin{tabular}{|c|c|c|c|}
\hline & Factor 1 & Factor 2 & Factor 3 \\
\hline Eigenvalue & 4.14 & 1.54 & 1.00 \\
\hline Varianza explicada & $34.46 \%$ & $12.86 \%$ & $8.36 \%$ \\
\hline \multicolumn{4}{|l|}{ Items } \\
\hline Estoy feliz de ser miembro de mi grupo étnico. & $.72^{a}$ & & \\
\hline Me siento fuertemente ligado(a) a mi grupo étnico. & .35 & .34 & .46 \\
\hline Me siento muy comprometido(a) con mi grupo étnico. & .32 & .55 & \\
\hline Me siento muy bien con mi tradición étnica o cultural. & .77 & & \\
\hline Estoy muy orgulloso(a) de mi grupo étnico. & .80 & & \\
\hline Últimamente me he dedicado a conocer más... & & .71 & \\
\hline Estoy consciente de mis „raíces étnicas“.... & .57 & .40 & \\
\hline Con el fin de aprender más sobre mi tradición cultural... & & .78 & \\
\hline Entiendo perfectamente lo que significa para mí pertenecer... & .52 & .55 & \\
\hline Asisto a grupos y organizaciones... & & & .81 \\
\hline Participo activamente de las tradiciones... & & & .55 \\
\hline $\begin{array}{l}\text { Asisto a organizaciones y participo en actividades qu } \\
\text { promueven... }\end{array}$ & & .43 & .64 \\
\hline
\end{tabular}

Nota. Sólo se presentan cargas factoriales superiores a .30. 
Estos análisis parecen reproducir la estructura tridimensional que originalmente se le otorgó a la escala. El primer factor con un valor propio de 4.14, explica aproximadamente un 34\% de la varianza de los ítems y puede ser claramente denominado "afirmación e identificación étnica". El segundo factor, que explica un $13 \%$ de la varianza de las respuestas con un valor propio de 1.54 , está conformado por la mayoría de los ítems que pretenden medir el "factor del desarrollo". Finalmente, un tercer factor emerge incorporando los ítems de "conductas étnicas", con un valor propio de 1 explicando aproximadamente el 8\% de la varianza explicada. Nótese, sin embargo, que algunos de los ítems tienen cargas factoriales sustanciales en otros factores. En particular, los ítems que tienden a medir conciencia de la propia etnicidad, originalmente destinados a medir elaboración étnica, tienen una carga igual o mayor en el factor de afirmación e identificación étnica en concordancia con la estructura bifactorial propuesta por Roberts et al. (1999). Por otro lado, la drástica caída de primer valor propio al segundo y el alto porcentaje de varianza explicada por este primer factor, comparado con el poco porcentaje de varianza explicada por el segundo y el tercer factor podrían dar pie para interpretar los resultados en términos de una solución factorial unidimensional. En efecto, análisis adicionales, forzando la extracción de un solo factor, muestran que todos los ítems tienen una carga factorial mayor a .40 en un factor general de identidad étnica. Los análisis confirmatorios resultan de gran utilidad en casos como este, en donde se desea discernir cuál de las estructuras plausibles representa de manera más adecuada la covariación de los ítems en estas muestras.

Análisis factoriales confirmatorios. Los análisis factoriales confirmatorios se llevaron a cabo tomando toda la muestra pero para cada grupo por separado, utilizando el programa EQS 5.7b. Esto permitirá examinar la idoneidad de los modelos a través de los diversos grupos. Recuérdese los tres modelos a evaluar: el primer modelo establece que la covariación de los 12 ítems es explicada total y exclusivamente por su relación con un factor latente general denominado identidad étnica. El segundo modelo predice tres subfactores covariantes: 1) afirmación e identificación étnica, 2) el componente del desarrollo y 3) prácticas étnicas. Aquí, la covariación de los ítems redactados para acceder a cada uno de éstos aspectos debería estar explicada exclusivamente por su relación con el respectivo constructo. La relación de los ítems con el factor que no deben medir es fijada a cero. Además el modelo supone que los factores covarían. El tercer modelo predice dos subfactores covariantes: afirmación e identificación étnica y exploración étnica. La estimación de los modelos se realizó sobre la base de la matriz de covarianzas de los ítems utilizando el método de máxima verosimilitud (Maximum Likelihood). El ajuste de los modelos fue evaluado con tres índices: el índice de ajuste comparativo (CFI), la raíz cuadrada del error de estimación (RMSEA) y el chi-cuadrado $\left(\chi^{2}\right)$. Estos índices proveen información acerca de la discrepancia entre la matriz de varianzas/covarianzas propuesta por el modelo teórico y la matriz de varianzas/covarianzas aportada por los sujetos (véase Hu y Bentler, 1995). En general, se dice que un modelo se ajusta aceptablemente a los datos si el índice de ajuste comparativo es mayor a .90, la raíz cuadrada del error de aproximación es igual o menor a .05 , y el valor chi-cuadrado es bajo y no es significativo (ver Maruyama, 1998). Debido a que el $\chi^{2}$ por lo general resulta significativo en muestras grandes como estas (aún cuando los modelos se ajusten adecuadamente; (ver Hu y Bentler, 1995), éste índice se utilizó sobre todo para evaluar si las diferencias de ajuste entre los modelos son estadísticamente significativas por medio del test de la diferencia del chi-cuadrado $\left(\Delta \chi^{2}\right)$. Complementariamente se examinaron los coeficientes de asociación entre las variables $(\beta)$ y los índices de modificación (LM Test y Wald Test). La tabla 4 presenta los resultados de este análisis. 
Tabla 4

Indices de ajuste de los tres modelos en cada grupo étnico

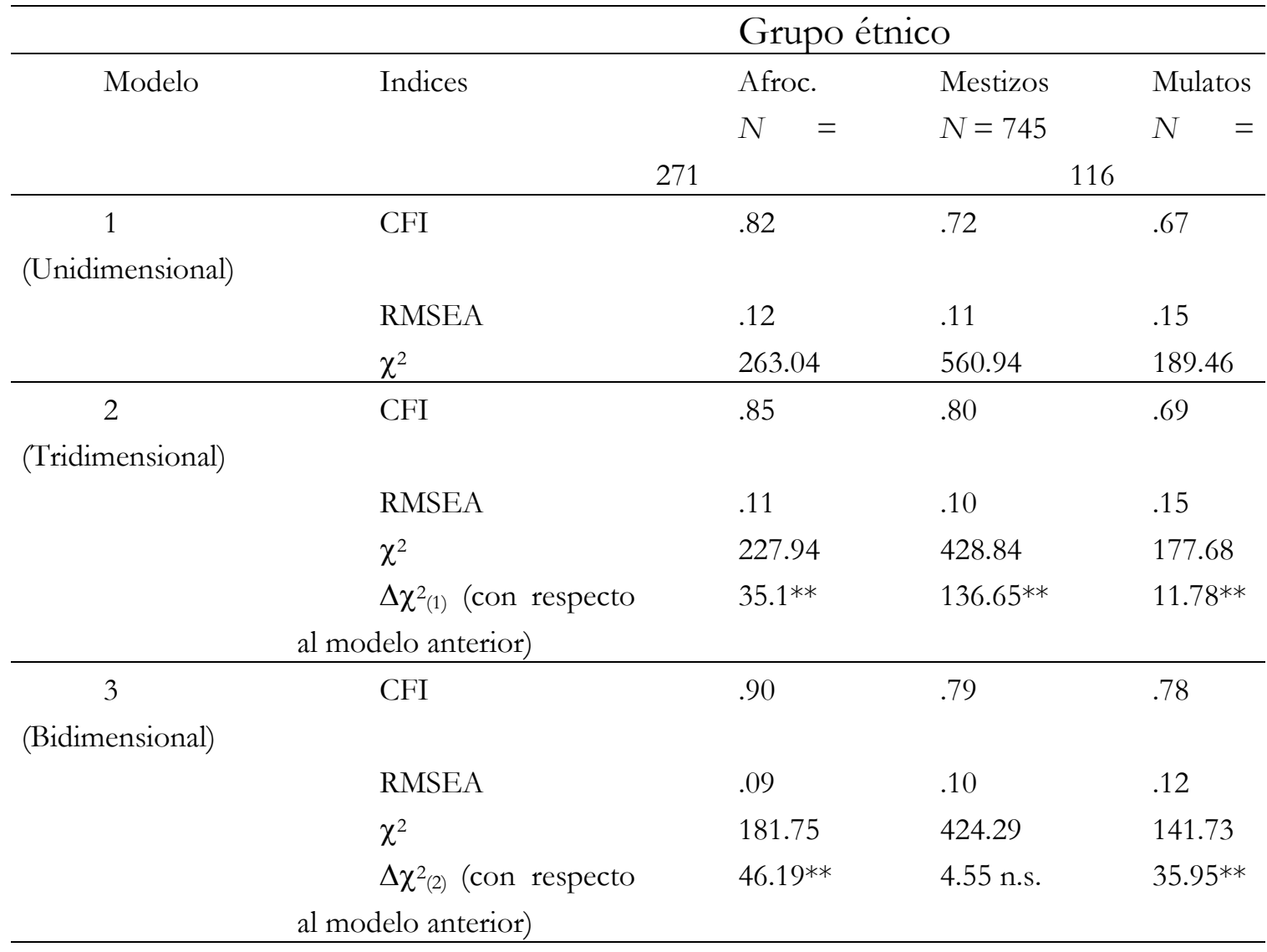

$* * p<.01$.

En general, todos los modelos muestran un ajuste muy pobre. Sin embargo, las pruebas de diferencia del chi-cuadrado indican que el modelo bifactorial tiene un ajuste significativamente superior (un $\chi^{2}$ significativamente más bajo) con respecto a los otros dos modelos en las muestras de jóvenes afrocostarricenses y mulatos y con respecto al modelo unidimensional en la muestra de jóvenes mestizos. En este grupo el modelo bidimensional no es significativamente superior al modelo tridimensional. Ahora bien, debido a que el interés primordial del instrumento es acceder a componentes de la identidad étnica comunes en distintos grupos étnicos, parece razonable, elegir el modelo bifactorial como aquel más indicado para describir la covaración de los ítems de la escala en el contexto costarricense. Este modelo fue examinado con mayor detalle (ver tabla 5). 
Tabla 5

Cargas factoriales de los ítems de la EIEM en los tres grupos estudiados

\begin{tabular}{|c|c|c|c|c|c|c|}
\hline \multicolumn{7}{|c|}{ Grupo étnico } \\
\hline \multirow[b]{4}{*}{ Item } & \multirow{2}{*}{\multicolumn{2}{|c|}{$\begin{array}{l}\text { Afrocostarricenses. } \\
\mathrm{N}=271\end{array}$}} & \multirow{2}{*}{\multicolumn{2}{|c|}{$\begin{array}{l}\text { Mestizos } \\
\mathrm{N}=745\end{array}$}} & \multirow{2}{*}{\multicolumn{2}{|c|}{$\begin{array}{l}\text { Mulatos } \\
\mathrm{N}=116\end{array}$}} \\
\hline & & & & & & \\
\hline & \multicolumn{6}{|c|}{ Factores } \\
\hline & 1 & 2 & 1 & 2 & 1 & 2 \\
\hline $\begin{array}{l}\text { Estoy feliz de ser miembro de } \mathrm{mi} \\
\text { grupo étnico. }\end{array}$ & $.65^{*}$ & - & .49 & - & .60 & - \\
\hline $\begin{array}{l}\text { Me siento fuertemente ligado(a) a mi } \\
\text { grupo étnico. }\end{array}$ & .60 & - & .52 & - & .51 & - \\
\hline $\begin{array}{l}\text { Me siento muy comprometido(a) con } \\
\text { mi grupo étnico. }\end{array}$ & .59 & - & .54 & - & .42 & - \\
\hline $\begin{array}{l}\text { Me siento muy bien con mi tradición } \\
\text { étnica o cultural. }\end{array}$ & .77 & - & .56 & - & .79 & - \\
\hline $\begin{array}{l}\text { Estoy muy orgulloso(a) de mi grupo } \\
\text { étnico. }\end{array}$ & .80 & - & .59 & - & .76 & - \\
\hline $\begin{array}{l}\text { Estoy consciente de mis "raíces } \\
\text { étnicas". }\end{array}$ & .72 & - & .56 & - & .73 & - \\
\hline $\begin{array}{l}\text { Entiendo perfectamente lo que } \\
\text { significa para mí pertenecer... }\end{array}$ & .71 & - & .64 & - & .55 & - \\
\hline $\begin{array}{l}\text { Con el fin de aprender más sobre mi } \\
\text { tradición cultural... }\end{array}$ & - & .59 & - & .57 & - & .58 \\
\hline $\begin{array}{l}\text { Últimamente me he dedicado a } \\
\text { conocer más... }\end{array}$ & - & .51 & - & .49 & - & .66 \\
\hline Asisto a grupos y organizaciones... & - & .53 & - & .36 & - & .36 \\
\hline $\begin{array}{l}\text { Participo activamente de las } \\
\text { tradiciones... }\end{array}$ & - & .64 & - & .50 & - & .37 \\
\hline $\begin{array}{l}\text { Asisto a organizaciones y participo en } \\
\text { actividades que promueven... }\end{array}$ & - & .66 & - & .63 & - & .77 \\
\hline
\end{tabular}

Nota. Factor 1 = identificación y afirmación étnica, factor $2=$ exploración de la identidad étnica.

Correlaciones entre los factores $=.68, .63$, y $.40\left(p_{\mathrm{s}}<.05\right)$ para el grupo afrocostarricense, mestizo y mulato.

- La carga factorial es fijada a cero.

* todas las cargas factoriales son significativas al .05.

Todos los ítems tienen una asociación significativa y alta con su respectivo factor (coeficientes estandarizados $\beta>$.40) sugiriendo que los ítems miden adecuadamente el constructo que se supone deben medir. En concordancia con la conceptualización de la identidad étnica propuesta aquí, las variables latentes se encuentran altamente correlacionadas en todos los grupos. Los coeficientes estandarizados $\beta$ de .68, .63, y .40 ( $\left.\phi_{\mathrm{s}}<.05\right)$ para el grupo afrocostarricense, mestizo y mulato indican que la escala accede a dos facetas de un mismo constructo. Como ya se indicó, este modelo presenta un ajuste pobre a los datos a pesar de ser el más adecuado de los tres que se evaluaron. Para conocer la fuente del desajuste se examinaron los índices de modificación 
(LM y Wald Tests) para cada grupo por separado. Sobre la base de los datos empíricos, el LM Test indica cuáles parámetros pueden ser admitidos para mejorar significativamente el ajuste del modelo, mientras el Wald Test indica cuáles parámetros son innecesarios y pueden ser eliminados sin que el ajuste del modelo empeore significativamente (Tabachnick y Fidell, 2001). En este caso en particular, las modificaciones propuestas por los tests indicarían cuáles ítems podrían cargar en otro factor, simultáneamente en los dos factores, o ser eliminados con el fin de aumentar la capacidad del modelo bifactorial de representar la covariación empírica. Debido a que todos los ítems cargan sustancial y significativamente en el factor propuesto, el Wald Test no sugirió ninguna eliminación de parámetros en ninguno de los grupos. El LM Test propuso algunas modificaciones (en todo caso no más de tres para los grupos afrocostarricense y mulato y cinco para el grupo mestizo), sugiriendo cargas factoriales simultáneas para algunos ítems. Por razones de espacio no se describirán éstas modificaciones en detalle. Resulta relevante sin embargo hacer notar que cuando el modelo es re-estimado incluyendo dichas modificaciones, se observa en efecto una mejora en el ajuste de los modelos, pero ninguna de las cargas factoriales propuestas por el test es esencialmente mayor que las cargas factoriales definidas por el modelo teórico en ninguno de los grupos. En virtud de la parsimonia y debido a que se trata de modificaciones particulares para cada grupo, se decidió no acoger las sugerencias del LM Test y asumir la bidimensionalidad de la escala en todas las muestras.

\section{Consistencia interna y características de la distribución}

Asumiendo que los 12 ítems tienen una estructura bidimensional (afirmación y exploración étnica) y que ambos factores se encuentran altamente relacionados, se realizaron análisis de confiabilidad para la escala y sus subescalas para cada grupo étnico utilizando como criterios el Alfa de Cronbach y los coeficientes de discriminación $\left(r_{\mathrm{t}}\right)$. Asimismo se examinaron las distribuciones de las puntuaciones medias de la escala y sus subescalas para cada grupo étnico (ver tabla 6).

Tabla 6

Puntuaciones medias, desviaciones estándar y coeficientes de consistencia interna (Alfa de Cronbach) de la EIEM y sus subescalas por grupo étnico

\begin{tabular}{|lcccccccccc|}
\hline & \multicolumn{3}{c}{ Afrocostarricenses } & \multicolumn{3}{c|}{ Mestizos } & \multicolumn{3}{c|}{ Mulatos } \\
\hline Escala & Media & DE & $\alpha$ & Media & DE & $\alpha$ & Media & DE & $\alpha$ \\
\hline EIEM & 4.64 & .92 & .86 & 3.99 & .84 & .78 & 4.20 & .87 & .81 \\
Afirmación e & 4.99 & .98 & .82 & 4.46 & .93 & .71 & 4.68 & .96 & .74 \\
Identificación étnica & & & & & & & & & \\
Exploración étnica & 4.15 & 1.13 & .67 & 3.32 & 1.07 & .61 & 3.55 & & 1.11 & .64 \\
\hline
\end{tabular}

Nota. Altas puntuaciones indican altos niveles en cada constructo.

Por lo general, Alfas iguales o mayores a .80 y coeficientes de discriminación iguales o mayores a .30 indican una buena consistencia interna de la escala (Mummendey, 1995). En este sentido, la escala muestra una consistencia interna bastante adecuada en todos los grupos como lo indican Alfas de Cronbach de $.86, .78$ y .81 para el grupo afrocostarricense, mestizo y mulato respectivamente. Los coeficientes de discriminación de los 12 ítems oscilan entre .33 y .60 con excepción de un ítem de conductas étnicas en el grupo mestizo que tiene un coeficiente de .29. Las subescala de afirmación étnica tiene una consistencia interna bastante aceptable (afrocostarricenses $=.82$, mestizos $=.71$ y mulatos $=.74$ ). Aquí también los coeficientes de discriminación de oscilan entre .33 y .66 con excepción de un ítem en el grupo mulato con un coeficiente de .25. La subescala de exploración étnica posee índices de consistencia mucho más modestos (Alfas de .67, .61 y .64 para el grupo afrocostarricense, mestizo y mulato, respectivamente), pero los coeficientes de discriminación son iguales o mayores a .30 en todos los grupos.

Recuérdese que las escalas tienen un rango teórico de 1 a 6 debido al formato de respuesta utilizado. En el grupo afrocostarricense, todas las escalas tienen un rango de 1 a 6 . La EIEM tiene 
un promedio de 4.64 y una desviación estándar de .92, la subescala de afirmación étnica tiene una media de 4.99 y una desviación estándar de .98 , y la subescala de exploración étnica tiene un promedio de 4.15 y una desviación típica de 1.13. La distribución de las puntuaciones medias es ligeramente asimétrica negativa, en particular para la subescala de afirmación étnica (asimetría = 1.64). El test Kolmogorov-Smirnov indica una desviación significativa con respecto a una distribución teórica normal para esta subescala $(Z=3.00 p<.01)$. En el grupo mestizo la EIEM tiene un rango de 1.42 a 5.83 con una media de 3.99 y una desviación estándar de .84, la subescala de afirmación étnica tiene un rango de 1.57 a 6, una media de 4.46 y una desviación estándar de .93, mientras que la subescala de exploración étnica tiene un rango de 1 a 5.80 con un promedio de 3.32 y una desviación típica de 1.07. La distribución de la subescala de afirmación étnica también muestra aquí una cierta asimetría hacia el extremo "alto" de la subescala (asimetría $=-.74, \mathrm{Z}=2.27$, $p<.01)$. En el grupo mulato la EIEM tiene un rango de 1.58 a $6(M=4.20, D S=.87)$, la subescala de identificación étnica tiene un rango de 1.43 a $6(M=4.68, D S=.96)$, mientras que la subescala de exploración étnica posee un rango de 1 a $6(M=3.55, D S=1.11)$. En este grupo, las puntuaciones de la escala de afirmación étnica tienden también a la asimetría negativa (skewness $=$ 1.15), en este caso sin embargo, no se trata de una desviación estadísticamente significativa $(Z=$ 1.38 , n.s.).

\section{Validez de constructo}

Correlaciones con otras escalas. Las correlaciones entre las subescalas $\left(r_{\mathrm{s}}=.56, .46\right.$ y .44 para el grupo afrocostarricense, mestizo y mulato), difieren ligeramente de las correlaciones entre los factores latentes. Esto debido a que los modelos de ecuaciones estructurales permiten separar la varianza asociada al error, la cual tiende a distorsionar las correlaciones. Aún así, las correlaciones indican una alta asociación entre los dos componentes. Para evaluar los criterios de validez se calcularon entonces correlaciones bivariadas entre la EIEM y las escalas de validación y correlaciones parciales entre cada subescala y las escalas de validación. Como en los análisis de regresión, las correlaciones parciales permiten detectar el efecto de una variable independiente (en este caso una de las subescalas de la EIEM) sobre las variables dependientes (las escalas de validación) manteniendo el efecto de la otra variable independiente (la otra subescala) constante (ver tabla 7).

\section{Tabla 7}

Correlaciones y correlaciones parciales entre la EIEM y sus subescalas con las escalas de validación

\begin{tabular}{|lllllllllll|}
\hline & \multicolumn{1}{l}{ Grupos } \\
\cline { 2 - 10 } & \multicolumn{1}{l}{ Afrocostarricenses } & \multicolumn{1}{c|}{ Mestizos } & \multicolumn{3}{c|}{ Mulatos } \\
\cline { 2 - 10 } & EIEM & Afir. $^{\mathrm{a}}$ & Expl. $^{\mathrm{b}}$ & MEIM & Afir. & Expl. & MEIM & Afir. $^{\mathrm{a}}$ & Expl. $^{\mathrm{b}}$ \\
\hline Autoestima & $.25^{* *}$ & $.32^{*}$ & -.11 & $.10^{* *}$ & $.16^{* *}$ & -.06 & $.24^{* *}$ & $.26^{* *}$ & -.05 \\
Identidad del yo & $.23^{* *}$ & $.25^{* *}$ & -.04 & $.20^{* *}$ & $.21^{* *}$ & -.00 & $.28^{* *}$ & $.37^{* *}$ & -.10 \\
Colectivismo & $.23^{* *}$ & .06 & $.17^{* *}$ & $.18^{* *}$ & $.15^{* *}$ & $.17^{* *}$ & $.18^{*}$ & .16 & .06 \\
Integración & $.37^{* *}$ & $.27^{* *}$ & .11 & $.24^{* *}$ & $.23^{* *}$ & .01 & $.30^{* *}$ & $.36^{* *}$ & -.03 \\
Asimilación & -.06 & $-.14^{*}$ & .08 & .07 & -.02 & $.10^{* *}$ & -.04 & $-.21^{*}$ & $.21^{*}$ \\
\hline
\end{tabular}

Nota . Afir. = Afirmación e Identificación étnica. Expl. = Exploración étnica.

a Correlaciones en esta columna son correlaciones parciales controlando exploración étnica.

b Correlaciones en esta columna son correlaciones parciales controlando afirmación étnica.

$* p<.05,{ }^{* *} p<.01$. 
La matriz de correlaciones muestra asociaciones moderadas y bajas (en parte quizá por la baja consistencia interna de las escalas de validación) pero significativas (la mayoría al .001) indicando que se tratan de mediciones de constructos relacionados pero claramente diferentes. Como se esperaba, la EIEM muestra relaciones positivas y estadísticamente significativas con indicadores de autoestima, identidad del yo, tendencias colectivistas y apoyo a la integración en todos los grupos. Jóvenes con altos niveles de identidad étnica global expresan mayores niveles en la definición y valoración del sí mismo, reconocen y valoran más la pertenencia a sus colectivos y apoyan más la integración étnica que aquellos que tienen bajas puntuaciones en identidad étnica.

La subescala de afirmación e identificación étnica también muestra relaciones consistentes con las escalas de validación. La subescala está positiva y significativamente asociada con las mediciones de autoestima, identidad del yo e integración en todos los grupos y negativamente asociada con la asimilación en los grupos afrocostarricense y mulato. De acuerdo a las hipótesis, entre más fuerte es el vínculo psicológico con el propio grupo de referencia, menor es la tendencia a abandonar las costumbres y tradiciones de dicho grupo. Finalmente, afirmación étnica tiene una relación moderada con las tendencias a la interdependencia en el grupo mestizo. La subescala de exploración étnica se comporta de manera menos consistente. En contra de lo esperado, ésta subescala parece estar desvinculada de mediciones de la identidad del yo y la autoestima en las muestras estudiadas y al parecer este componente está poco relacionado con conductas y actitudes interétnicas como la integración. La exploración étnica está además positivamente ligada con la asimilación en los grupos mestizo y mulato.

Diferencias en la identidad étnica por grupo étnico. Debido a que existen diferencias significativas de edad entre los grupos y la escala es teóricamente sensible al desarrollo, primero se examinaron las diferencias en identidad étnica entre los grupos por medio de un análisis de covarianza múltiple (MANCOVA) con las puntuaciones de la EIEM y sus subescalas como variables dependientes, la etnicidad como factor y la edad de los jóvenes como covariante. Ya que no se observó ningún efecto multivariado de la edad (Wilk`s Lambda $\mathrm{F}(3,1161)=.28$ n.s.), se prosiguió con un análisis multivariado (MANOVA). Análisis adicionales revelaron que ni el estrato socioeconómico, el lugar de residencia (Limón y San José) ni el género tienen un efecto multivariado significativo en las puntuaciones de identidad étnica (Wilks's Lamda $\mathrm{F}_{\mathrm{s}}<1$, n.s.). Tampoco lo tienen las interacciones entre éstas variables (Wilks's Lamda $\mathrm{F}_{\mathrm{s}}<2.1$, n.s.). La tabla 8 presenta las puntuaciones medias de la EIEM y sus subescalas por grupo étnico.

Tabla 8

Puntuaciones medias de la EIEM y sus subescalas por grupo étnico

\begin{tabular}{|c|c|c|c|c|}
\hline \multirow{2}{*}{ Grupo étnico } & & \multicolumn{2}{|c|}{ Escalas } & \multirow[b]{2}{*}{ Exploración } \\
\hline & & MEIM & Afirmación & \\
\hline \multirow[t]{2}{*}{ Afrocostarricenses } & Media & $4.64^{\mathrm{a}}$ & $4,99^{\mathrm{a}}$ & $4.15^{\mathrm{a}}$ \\
\hline & $\mathrm{DE}$ & .92 & .98 & 1.13 \\
\hline \multirow[t]{2}{*}{ Mestizos } & Media & $3.99^{\mathrm{b}}$ & $4.46^{\mathrm{b}}$ & $3.32^{\mathrm{b}}$ \\
\hline & DE & .84 & .93 & 1.07 \\
\hline \multirow[t]{2}{*}{ Mulatos } & Media & $4.20^{c}$ & $4,68^{\mathrm{b}}$ & $3.55^{\mathrm{b}}$ \\
\hline & $\mathrm{DE}$ & .87 & .96 & 1.11 \\
\hline \multirow[t]{2}{*}{ Total } & Media & 4.17 & 4.62 & 3.55 \\
\hline & $\mathrm{DE}$ & .91 & .97 & 1.14 \\
\hline
\end{tabular}

Nota. Altas puntuaciones indican altos niveles en los constructos. En cada columna, los promedios con diferente letra difieren significativamente al .05 en la prueba Tukey HSD.

Los resultados revelaron el efecto multivariado esperado de la etnicidad de los participantes sobre la identidad étnica (Wilk`s Lambda $F(3,1161)=19.99, p<.001$ ). A nivel univariado, los 
resultados muestran que tal efecto puede ser observado tanto en la identidad étnica global $\left(F(2,1170)=59.32, p<.001, \eta^{2} .09\right)$ como en la afirmación étnica $\left(F(2,1170)=33.17, p<.001, \eta^{2}\right.$ $=.05)$ y la exploración étnica $\left(F(2,1170)=59.42, \mathrm{p}<.001, \eta^{2}=.09\right)$. La prueba Tukey HSD para comparaciones post hoc reveló que los jóvenes afrocostarricenses tienen el promedio en la identidad étnica global más alto, seguidos por los jóvenes mulatos, mientras que los jóvenes mestizos muestran los niveles más bajos (todas las $p_{\mathrm{s}}<.05$ ). Las subescalas siguen este mismo patrón, pero aquí los promedios de los mulatos y los mestizos no difieren significativamente.

\section{Discusión}

El objetivo del presente estudio ha sido ofrecer un instrumento de medición del significado subjetivo de pertenecer a categorías étnicas en jóvenes costarricenses de distintas procedencias étnicas. A la vez se ha buscado contribuir al análisis de la identidad étnica y sus componentes en esta población.

En concordancia con investigaciones recientes en diversos contextos culturales, el presente estudio muestra claramente que la identidad étnica está muy lejos de ser un constructo unidimensional evidenciando varios aspectos relacionados pero a la vez claramente distinguibles de la vivencia subjetiva de pertenecer a un grupo étnico. El primer aspecto a resaltar es la evidencia, indirecta pero muy clara, en favor de un componente cognitivo de la identidad étnica. Los resultados muestran que las personas (cuando son interpeladas) utilizan categorías étnicas como parte de la definición que hacen de sí mismas. Así, los resultados revelan que las categorías sociales no sólo sirven de marco de referencia para organizar la información del mundo social y guiar la acción, sino también para proveer al individuo de información sobre lo que él es como persona. Los datos señalan también que la etiqueta étnica utilizada por los jóvenes para describirse a sí mismos no siempre concuerda con la etnicidad atribuida a los padres (ver Phinney y Alpuria, 1996, quienes reportan resultados similares), evidenciando así que la afiliación étnica no necesariamente responde a criterios objetivos como la apariencia física o el origen geográfico. Obviamente los marcadores étnicos objetivos son importantes en la medida que representan la base del significado social y psicológico asociados a ellos. Sin embargo, reconocer esta distinción resulta de gran valor por varias razones. Quizá la más importante de ellas es evitar la confusión entre etnicidad, el hecho concreto de nacer dentro de un grupo étnico particular (o varios), y la significación subjetiva de pertenecer a tal(es) grupo(s) étnico(s). En la práctica, sin embargo, la autoidentificación étnica ha sido inferida por los investigadores a partir de criterios como el color de la piel de sus entrevistados sin preguntarles si ellos se consideran a sí mismos miembros del grupo étnico estudiado.

Aparte de la autoidentificación étnica, los análisis confirman la presencia de dos componentes adicionales apoyando el modelo bidimensional propuesto por Roberts et al. (1999). El primer componente, la afirmación e identificación étnica, refleja la importancia, el significado afectivo y la connotación valorativa de pertenecer a un grupo étnico. Este factor ha sido conceptualizado desde la TIS como un importante componente del sí mismo encargado, en gran medida, de regular las actitudes y conductas intergrupales. En línea con estas premisas, los resultados indican que actitudes positivas hacia la propia etnicidad están asociadas a altos niveles de valoración personal en todos los grupos étnicos estudiados. Asimismo, la afirmación e identificación étnica está positivamente relacionada con la tendencia a apoyar la diversidad étnica y negativamente asociada con políticas asimilacionistas. Resultados similares han sido reportados en grupos étnicos muy distintos a los estudiados en esta investigación (Moran, Fleming, Somervell, y Manson, 1999; Valk y Karu, 2001). Así, los datos parecen demostrar que la relación psicológica con el grupo étnico de referencia tiene un impacto importante tanto en la forma como nos vemos a nosotros mismos, como en la manera en que vemos a los miembros de otros grupos étnicos e interactuamos con ellos.

Ahora bien, estos significados varían de un grupo étnico a otro. Tal y como se esperaba, miembros de grupos étnicos minoritarios están más conscientes de sus orígenes étnicos, otorgan más importancia a su pertenencia étnica y se identifican más fuertemente con su grupo étnico de referencia que los jóvenes del grupo étnico mayoritario. Jóvenes de procedencia bicultural se ubican en el medio de estos dos extremos. Esto sugiere que la valoración subjetiva de la etnicidad depende del grupo étnico de referencia, sus particularidades culturales e históricas y sobre todo su estatus social. El grupo étnico de referencia es, además, un importante moderador del efecto de la 
afirmación e identificación étnica sobre otras variables psicosociales. Así por ejemplo, mientras la afirmación e identificación étnica están negativamente asociadas con la asimilación en el grupo afrocostarricense y mulato, en el grupo mayoritario no se observa covariación alguna entre esas variables. Esto también es explicable en términos de la dinámica de las relaciones de poder entre los grupos: para miembros de grupos étnicos minoritarios la asimilación implica abandonar las prácticas culturales que le dan sentido a sus experiencias psicosociales, para el grupo mayoritario no.

El segundo componente, la exploración étnica, tiene su sentido desde las perspectivas del desarrollo que asumen la formación de la identidad étnica como un proceso que tiene lugar a través del tiempo en donde las personas toman decisiones sobre el papel que juega la etnicidad en sus bosquejos de vida. Este componente, incorpora también la participación en las prácticas culturales del grupo étnico de referencia. Al parecer, en estos grupos las prácticas culturales forman parte integral de este proceso de toma de decisiones, como también fue constatado por Roberts et al. (1999) en sus muestras. Esto se sustenta en conceptualizaciones de autores como Cross (1990) y Phinney (1990), para quienes el proceso de formación de la identidad étnica implica una "inmersión" activa en la propia cultura que permite evaluar, acoger o rechazar los ofrecimientos culturales. El explorar la propia cultura parece depender también del grupo étnico de pertenencia y sus condiciones sociales. Los jóvenes del grupo afrocostarricense tienden a explorar más sus orígenes étnicos que los jóvenes mulatos y mestizos.

Habría que aclarar, sin embargo, que los resultados que involucran este componente son altamente inconsistentes y deben interpretarse con reserva. Este factor tiene índices de confiabilidad muy bajos y no parece estar ligado ni a la identidad personal ni a la autoestima. Este componente tiene, además, poca relación con conductas intergrupales como la integración o asimilación en el grupo afrocostarricense y hasta se encuentra positivamente ligado con asimilación en los jóvenes mestizos y mulatos, en contra de los supuestos teóricos. Finalmente, los datos presentados no dan pie para asegurar que esta dimensión refleje un proceso de formación o desarrollo en esta muestra. Con los datos disponibles es difícil adelantar una interpretación para estos patrones de correlación. Se podría pensar que estos son el producto de problemas de multicolinearidad en el cálculo de las correlaciones parciales ya que los factores están altamente correlacionados. En este sentido, estos datos resultan de gran relevancia, pues no se conocen hasta la fecha estudios en donde las subescalas hayan sido examinadas de esta manera. Investigaciones anteriores han basado sus interpretaciones sobre correlaciones de la escala en su totalidad y escalas de validación (ej. Roberts et al., 1999). Las correlaciones parciales permiten acercarse a la contribución relativa de cada componente de la identidad étnica en la definición y valoración del sí mismo, y la regulación del comportamiento social. En este caso, el componente de exploración parece tener un aporte limitado.

La escala posee otras limitaciones en el contexto costarricense. Una de las más importantes es que el formato utilizado para acceder a la autoidentificación étnica no permite evaluar directamente la distinción de un componente cognitivo de la identidad étnica. Se podría pensar que los procesos de categorización étnica generan automáticamente ciertas emociones y evaluaciones asociadas con dicha categoría, por lo que este tipo de distinciones se hacen innecesarias a un nivel práctico. Esta diferenciación es sin embargo útil si se toma en cuenta que cuando los individuos nos identificamos como miembros de una categoría étnica, no necesariamente expresamos si este hecho es relevante para nuestras vidas; la importancia y el vínculo afectivo con tal categoría la expresamos cuando nos sentimos identificados con nuestro grupo étnico y afirmamos nuestra etnicidad. Como se anotó anteriormente, la evidencia presentada aquí en favor de esta distinción es más bien indirecta (en el sentido de que a lo interno de cada categoría étnica se observa varianza en los otros dos componentes). Ahora bien, estudios en los que se han utilizado otros formatos de medición para acceder a éste componente (escalas Likert por ejemplo) han demostrado que tal distinción tiene también un correlato empírico (Ellemers et al., 1999; Klink et al., 1997). Futuras investigaciones en Costa Rica podrían concentrarse en medir más adecuadamente este componente para conocer su contribución particular al sentimiento de pertenencia a los colectivos étnicos.

En este estudio tampoco se observaron indicios de una distinción entre el componente afectivo y evaluativo de la identidad étnica en ningún grupo étnico. La covariación de estos ítems parece estar explicada por una sola variable latente. Habrá que recordar, que según la TIS la probabilidad de expresar una identificación positiva con el endogrupo es mayor cuando el grupo es evaluado positivamente y viceversa. Esto en virtud del papel central que tienen las categorías sociales en la satisfacción de una necesidad personal muy común en sociedades occidentales: tener una percepción del sí mismo coherente y positiva (ver Hogg y Mullin, 1999; Tajfel y Turner, 1969). 
Es quizá por ello que en otros estudios tampoco se han podido distinguir estos componentes empíricamente (Ellemers et al., 1999; Luhtanen y Crocker, 1992), y quizá por ello es que la autora de la escala no intenta separar estos componentes conceptualmente. Sin embargo, esta distinción se torna importante, al menos teóricamente, para una mayor comprensión de la relación psicológica de miembros de grupos étnicos discriminados con su grupo de referencia. Debido a que la etnicidad es una adscripción y no una elección, estos dos componentes pueden contribuir de manera diferente a la identidad étnica de personas que se ven enfrentadas cotidianamente con imágenes negativas de sus propios grupos. En efecto, algunos estudios con miembros de grupos étnicos minoritarios han mostrado que la identificación étnica no se ve necesariamente disminuida por el reconocimiento de que el propio grupo tiene un estatus social bajo o es objeto de discriminación (Crocker, Luhtanen, Blaine, y Broadnax, 1994; Mlicki y Ellemers, 1996). Por el contrario, estudios recientes muestran que la percepción de discriminación lleva a miembros de grupos discriminados a aumentar su identificación con el grupo étnico de referencia como parte de las estrategias de enfrentamiento al estigma (Branscombe, 2001). La investigación futura podría orientarse a indagar más profundamente sobre la significancia teórica y práctica de distinguir entre un componente evaluativo y afectivo de la identidad étnica en nuestro medio.

Finalmente, las puntuaciones medias de la escala de afirmación étnica presentan desviaciones significativas con respecto a una distribución teórica normal en el grupo afrocostarricense y mestizo, evidenciando muchas puntuaciones altas y pocas bajas. Esto no es de extrañar en instrumentos de papel y lápiz que miden actitudes, sobre todo cuando se trata de una evaluación de la propia persona u otros objetos sociales cargados de gran significado personal. Sin embargo, y aunque se trate de desviaciones pequeñas, es necesario que la investigación futura indague más a fondo en estos aspectos psicométricos. Ello nos aseguraría que las respuestas a los ítems reflejan el constructo que se pretende medir y no un artefacto producido por la deseabilidad social. En este sentido, el instrumento podría también ser mejorado si se incluyen ítems negativos que ayuden a controlar el efecto de tales tendencias.

A pesar de esto, la escala goza de importantes ventajas. Los patrones de relación entre los ítems y los constructos son muy similares en los tres grupos estudiados, indicando que la escala tiene la capacidad de acceder a elementos de la identidad étnica comunes a varios grupos étnicos. Esto trae consigo grandes beneficios para la comparación intra e intercultural. La escala tiene índices de consistencia alrededor del .80, lo que la hace bastante confiable. Con contadas excepciones, los ítems presentan coeficientes de discriminación iguales o mayores de .30, indicando que tienen la capacidad de discernir entre niveles altos y bajos de la identidad étnica. La escala y su principal componente presentan correlaciones consistentes con otras variables psicosociales, demostrando su validez de constructo. Finalmente el instrumento es sensible a diferencias entre grupos étnicos.

Ciertamente se necesita mayor investigación para mejorar el instrumento, sobre todo en grupos étnicos distintos a los estudiados aquí. Sin embargo la escala tiene las propiedades psicométricas necesarias para ser utilizada en jóvenes costarricenses de distintas procedencias culturales. Con ello se abren muchas posibilidades de investigación sobre la identidad étnica en el medio costarricense. La invitación es a utilizarla, mejorarla y así contribuir a un mejor conocimiento sobre la vivencia subjetiva de la diversidad étnica en Costa Rica.

\section{Referencias}

Aboud, F. E. y Doyle, A. B. (1995). The development of in-group pride in Black Canadians. Journal of Cross-Cultural Psychology, 26, pp. 243-254.

Allport, G. (1954). The nature of prejudice. Reading, MA: Perseus Book Publishing.

Berry, J. W. (1984). Cultural relations in plural societies: Alternatives to segregation and their sociopsychological implications. En Miller, B. y Brewer, M. (Eds.). Groups in contact: The psychology of desegregation (pp. 11-27). London: Academic Press. 
Berry, J. W.; Kim, U., Power; S., Young, M. y Bujaki, M. (1989). Acculturation attitudes in plural societies. Applied Psychology: An International Review, 38, pp. 185-206.

Branscombe, N. (2001). Meanings and consequences of perceived discrimination in disadvantaged and privilieged groups. Paper presented at the EAESP/SPSSI small meeting "Prejudice and Racism". May, 23-26, 2000 in Granada, Spain.

Crocker, J.; Luhtanen, R.; Blaine, B. y Broadnax, S. (1994). Collective self-esteem and psychological well-being among White, Black, and Asian college students. Personality and Social Psychology Bulletin, 20, pp. 503-513.

Cross, W. E. (1991). Shades of black: Diversity in African-American identity. Philadelphia: Temple University Press.

Duncan, Q. y Powel, P. (1988). Teoría y práctica del racismo. San José, C.R.: Editorial DEI.

Ellemers, N.; Kortekaas, P. y Ouwerkerk, J. W. (1999). Self-categorization, commitment to the group and group self-esteem as related but distinct aspects of social identity. European Journal of Social Psychology, 29, pp. 371-389.

Erikson, E. (1973). Identität und Lebenszylklus: Drei Aufsätže. Frankfurt am Main: Suhrkamp.

Helms, J. E. (1990). Black and white racial identity: Theory, research and practice. Westpport, CT: Greenwood.

Hogg, M. A. y Mullin, B. (1999). Joining groups to reduce uncertainty: Subjective uncertainty reduction and group identification. In Abrams, D. y Hogg, M. A. (Eds.). Social identity and social cognition (pp. 249-279). Oxford: Blackwell.

Hu, L. y Bentler, P.M. (1995) Evaluating model fit. In Hoyle, R.H. (Ed.). Structural equation modeling: Concepts, issues and applications (pp. 76-100). London: Sage.

Hui, H. (1988). Measurement of Individualism-Collectivism. Journal of Research in Personality, 22, pp. 17-36.

Ichiyama, M.; McQuarrie, E. y Ching, K. (1996). Contextual influences on ethnic identity among Hawaiian students in the mainland United States. Journal of Cross-Cultural Psychology, 27, pp. 458-475.

Klink, A.; Mummendey, A.; Mielke, R. y Blanz, M. (1997). A multicomponent approach to group identification: Results from a field study in East Germany. Jena: Unveröffentlicbter Forschungsbericht des Lebrstubls Sozial Psychology, Nr. 10.

Lorenzo-Hernández J. y Ouellette, S. (1998). Ethnic identity, self-esteem, and values in Dominicans, Puerto Ricans, and African Americans. Journal of Applied Social Psychology, 28, pp. 20072024.

Luhtanen, R. y Crocker, J. (1992). A collective self-esteem scale: Self evaluation of one's social identity. Personality and Social Psychology Bulletin, 18, 302-318.

Martínez, R. y Dukes, R. (1997). The effects of ethnic identity, ethnicity, and gender on adolescent well-being. Journal of Youth and Adolescence, 26, pp. 503-516.

Maruyama, G. M. (1998). Basics of structural equation modeling. London: Sage.

Mead, G. H. (1934). Mind, self, and society. Chicago: University of Chicago Press.

Meléndez, C. y Duncan, Q. (1981). El negro en Costa Rica. San José, C.R.: Editorial Costa Rica.

Mlicki, P. y Ellemers, N. (1996). Being different or being better? National stereotypes and identifications of Polish and Dutch students. European Journal of Social Psychology, 26, pp. 97-114. 
Moran, J.R.; Fleming, C.M.; Somervell, P. y Manson, S.M. (1999). Measuring bicultural ethnic identity among American Indian adolescents: A factor analysis study. Journal of Adolescent Research, 14, pp. 405-426.

Mummendey, H.D. (1995). Die Fragebogenmethode. Göttingen: Hogrefe.

Phinney, J. (1990). Ethnic identity in adolescents and adults: Review of research. Psychological Bulletin, 108, 499-514.

Phinney, J. (1992). The multi-group ethnic identity measure: A new scale for use with adolescents and young adults from diverse groups. Journal of Adolescent Research, 7, pp. 156-176.

Phinney, J. y Alpuria, L. (1996). At the interface of cultures: Multiethnic/multiracial high school and college students. The Journal of Social Psychology, 136, pp. 139-158.

Phinney, J.; Cantu, C. L. y Kurtz, D. A. (1997). Ethnic and American identity as predictors of self-etseem among African American, Latino and White adolescents. Journal of Youth and Adolescence, 26, pp. 165-185.

Roberts, R.E.; Phinney, J. S.; Masse, L.C.; Chen, Y. R.; Roberts, C. R. y Romero, A. (1999). The structures of ethnic identity of young adolescents from diverse ethnocultural groups. Journal of Early Adolescence, 19, pp. 301-322.

Rosenberg, M. (1965). Society and the adolescent self-image. Princeton, NJ: Princeton University Press.

Rosenthal, D. y Feldman, S. (1992). The nature and stability of ethnic identity in Chinese youths: Effects of length of residence in two cultural contexts. Journal of Cross-Cultural Psychology, 23, pp. 214-227.

Rosenthal, D.; Gurney, R. y Moore, S. (1981). From trust to intimacy: A New inventory for examining Erikson's stages of psychosocial development. Journal of Youth and Adolescence, 10, pp. 525-537.

Sawyers, K. y Perry, F. (1996). Los Afrocentroamericanos: redescubrimiento de la herencia africana. Costa Rica. In Minority Rights Group (Ed.). Los Afrocentroamericanos: El redescubrimiento de la herencia africana (pp. 54-62). San José, C.R.: MRG.

Sellers, R. M.; Smith, M. S.; Shelton, J. N.; Rowley, S. A. y Chavous, T. M. (1998). Multidimensional model of racial identity: A reconceptualization of African American identity. Personality and Social Psychology Bulletin, 2, pp. 18-39.

Tabachnick, B. G. y Fidell, L.S (2001). Using multivariate statistics. Boston: Ally and Bacon.

Tajfel, H. (1981). Human groups and social categories: Studies in social psychology. Cambridge: Cambridge University Press.

Tajfel, H. y Turner, J. (1979). An integrative theory of intergroup conflict. In Worchel, S. y Austin, W. G. (Eds.). The social psychology of intergroup relations (pp. 33-47). Monterey, CA: Brooks/Cole.

Triandis, H.; Bontempo, K.; Villareal, M.; Asai, M. y Lucca, N. (1988). Individualism and collectivism: Cross-cultural perspectives on self-ingroup relationships. Journal of Personality and Social Psychology, 54, pp. 232-338.

Turner, J. C.; Oaks, P. J.; Haslam, A. y McGarty, C. (1994). Self and collective: cognition and social context. Personality and Social Psychology Bulletin, 20, pp. 454-463. 
Valk, K. y Karu, K. (2001). Ethnic attitudes in relation to ethnic pride and ethnic differentiation. Journal of Social Psychology, 141, pp. 583-602.

Van Dick, R. y Wagner, U. (in prep.). Group identification among schoolteachers: dimensions, foci, and correlates. Manuscript under editorial review.

Van Dick, R.; Wagner, U.; Adams, C. y Petzel, T. (1997). Einstellungen zur Akkulturation: Erste Evaluation eines Fragebogens an sechs deutschen Stichproben. Gruppendynamik, 28, pp. 83-92.

Verkuyten, M. (1990). Self-esteem and the evaluation of ethnic identity among Turkish and Dutch adolescents in the Netherlands. The Journal of Social Psychology, 130, pp. 285-297.

Wagner, U. (1994). Eine sozialpsychologische Analyse von Intergruppenbeziehungen. Göttingen: Hogrefe.

Ward, C. y Kennedy, A. (1994). Acculturation strategies, psychological adjustment, and sociocultural competence during cross-cultural transitions. International Journal of Intercultural Relations, 18, pp. 329-343.

Wegener, D.T. y Fabrigar, L.R. (2000). Analysis and design for nonexperimental data: Addressing causal and noncausal hypotheses. In Reis, H. T. y Judd, C. M. (Eds.). Handbook of research methods in social and personality psychology. (pp. 412-450). Cambridge: Cambridge University Press. 